\title{
THE GRAVIMETRIC DETERMINATION OF PREGNANEDIOL
}

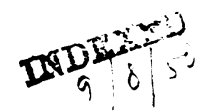

\author{
IN URINE \\ BY \\ SIDNEY LIONEL TOMPSETT \\ From the Biochemical Department, Royal Infirmary, Glasgow
}

(RECEIVED FOR PUBLICATION FEBRUARY 2, 1950)

The methods of Venning and Browne (1937) and Astwood and Jones (1941) form the basis of most of the methods that have been described for the determination of pregnanediol in human urine. In the former, the pregnanediol is separated as the glucuronidate, the amount being determined gravimetrically. In the latter, the urine is subjected to acid hydrolysis and the amount of free pregnanediol determined gravimetrically. There have been a number of criticisms of the Venning-Browne method. The chief is that the isolated pregnanediol glucuronidate may be contaminated with a 20-ketosteroid. In a recent study, I (Tompsett, 1949 ; and unpublished data) found that, although 20-ketosteroids exist in appreciable quantities in the urine of late pregnancy, they are not found in appreciable quantities in the urine of non-pregnant subjects or in early pregnancy, except possibly in cases of adrenocortical tumour.

Quantitative methods have been described for the determination of pregnanediol in quantities of urine less than the 24-hour output (Sommerville, Marrian, and Kellar, 1948 ; Henderson, Maclagan, Wheatley, and Wilkinson, 1949). The amount of pregnanediol is determined colorimetrically and this necessitates the provision of pregnanediol as a standard. In this laboratory, because there has never been any difficulty in obtaining such, complete 24-hour collections have always been used. A modified Astwood and Jones (1941) method is employed. No standard substance is required and the actual time of weighing is small if one employs a modern balance. Although it takes two and a half days to obtain a result, we have found that the process can be broken up into a number of convenient stages which fit into the general routine of the laboratory. In an extensive investigation, it has been found that the excretion of pregnanediol by the male is less than $1 \mathrm{mg}$. per day, and in the female during the reproductive phase of life the maximum is 4.5-6.5 mg. per day. In late pregnancy it has been found that pregnanediol as determined by this method agrees very closely with the content of non-ketonic alcohols of the neutral steroid fraction (Tompsett, 1949).

Materials and Method

Reagents.-The following reagents are required :

1. Redistilled toluol.

2. Concentrated hydrochloric acid.

3. Aqueous $10 \%$ sodium hydroxide.

4. Aqueous $0.1 \mathrm{~N}$. sodium hydroxide.

5. Absolute alcohol (redistilled). 
Apparatus.-The apparatus required is :

1. Two-litre flasks fitted with reflux condensers (all-glass).

2. Vacuum distillation apparatus (all-glass) fitted with 500-ml. flasks.

3. 100-ml. conical flasks.

4. Two-litre separating funnels.

5. Seven-cm. No. 42 Whatman filter papers.

The entire 24-hour collection of urine is introduced into a 2-litre flask fitted with a reflux condenser together with $1 / 10$ of its volume of concentrated hydrochloric acid and $200 \mathrm{ml}$. toluol. The mixture is heated to boiling, the boiling continued for 15 minutes, and then cooled rapidly in running water.

The mixture is transferred to a 2-litre separating funnel. The toluol is separated and the aqueous fraction extracted with two further quantities of $200 \mathrm{ml}$. toluol. The combined toluol extracts are washed twice with two $100 \mathrm{ml}$. quantities of $10 \%$ sodium hydroxide and twice with $100 \mathrm{ml}$. quantities of water. The toluol extract is evaporated down to dryness in a $500 \mathrm{ml}$. flask attached to a vacuum still. It is essential to have the flask heated by a water bath and to begin heating from the cold, otherwise trouble from "bumping" may be encountered.

The dry residue is dissolved in $10 \mathrm{ml}$. absolute alcohol, the solution being transferred to a $100 \mathrm{ml}$. conical flask, and $40 \mathrm{ml}$. hot (about $70^{\circ} \mathrm{C}$.) $0.1 \mathrm{~N}$. sodium hydroxide solution added to the alcoholic solution. (This process can be used to transfer completely the contents of the $500 \mathrm{ml}$. flask into the $100 \mathrm{ml}$. conical flask.) The mixture is allowed to cool to room temperature after which the flask is placed in a refrigerator $\left(5^{\circ}\right.$ C.) overnight. The contents of the flask are filtered through a $7 \mathrm{~cm}$. No. 42 Whatman filter paper. The residue is washed with $40 \mathrm{ml}$. cold water $\left(5^{\circ} \mathrm{C}\right.$.). (The cold water should be transferred from the original conical flask.) The filter paper containing the residue is put back into the original conical flask and $10 \mathrm{ml}$. absolute alcohol added. When solution of pregnanediol has been effected, $40 \mathrm{ml}$. of hot water (about $70^{\circ} \mathrm{C}$.) is added. The mixture is allowed to cool to room temperature after which it is placed in a refrigerator $\left(5^{\circ} \mathrm{C}\right.$.) overnight. The contents of the flask are then filtered through a $7 \mathrm{~cm}$. No. 42 Whatman filter paper. The residue is washed with $40 \mathrm{ml}$. cold water $\left(5^{\circ} \mathrm{C}\right.$.). The residue on the filter paper is dissolved in about $40 \mathrm{ml}$. absolute alcohol (contained in the original conical flask), the fi'trate being collected in a weighed $50 \mathrm{ml}$. beaker. The alcohol is evaporated off in a hot air oven maintained at $100^{\circ} \mathrm{C}$. The dry beaker is allowed to cool in a desiccator. The increase in weight represents pregnanediol separated.

\section{Summary}

The determination of pregnanediol in urine by a gravimetric method is described.

\section{REFERENCES}

Astwood, E. B., and Jones, G. E. S. (1941). J. biol. Chem., 137, 397.

Henderson, J., Maclagan, N. F., Wheatley, V. R., and Wilkinson, J. H. (1949). J. Endocrinol., 6, 41. Sommerville, I. F., Marrian, G. F., and Kellar, R. J. (1948). Lancet, 2, 89.

Tompsett, S. L. (1949). J. Endocrinol., 6, 192.

Venning, E. H., and Browne, J. S. L. (1937). Endocrinology, 21, 711. 